\title{
Open Innovation as a Tool of Strategic Management
}

\author{
Pavla MATULOVÁ, Kamil KUČA \\ University of Hradec Králové, Hradec Králové, Czech Republic \\ pavla.matulova@gmail.com; kamil.kuca@uhk.cz
}

\begin{abstract}
The open innovation phenomenon has developed from a small club of innovation practitioners, mostly active in high-tech industries, to a widely discussed and implemented innovation practice. Simultaneously, a small community of management researchers has recently developed into an established research field. Once a field grows rapidly there is a danger that it may become a short-term fashion. This special issue reports on recent research evidence to further develop the open innovation research field. South Moravian in Czech Republic region started to support companies and help them with organization of open innovation session. The tool perspective: Opening up the innovation process requires a set of instruments. Those tools, for example, enable customers to create or configure their own product with tools kits or enable companies to integrate external problem solvers or idea creators. Currently a broad awareness of open innovation and its relevance to corporate R\&D. Aim of paper is research and measure the results after ten years since Open innovation has been supported by region government in South Moravian region in Czech republic and was implemented in innovation strategy of this region. Regional strategy is partnership of South Moravian companies, local scientists, public authorities and other parties connected to development in the region. Open innovation has become important part of strategic management and has become a well-established, though still somewhat fragmented, academic discipline.
\end{abstract}

Keywords: Strategic Management, Open Innovation Session, Regional Strategy.

\section{$1 \quad$ Features of regional innovation strategy}

South Moravia has got a traditional strong and expanding basis in the research and development area formed by college students and scientists. The structure of these students and scientists is also favorable because it is focused on disciplines of biology and engineering. The key approach how to improve the situation is to support innovative small and medium enterprises with a high added value that direct their attention to the introduction of novel and better products and services and also to the introduction of new approaches. A political consensus of all parties involved represent a cardinal advantage in a process of introducing the system supporting the innovative business. Universities, the regional political representation and 
representatives of the City of Brno have managed to find a common ground and came to an agreement regarding goals that are mentioned the Regional Innovation Strategy. In the years 2014-2020, the South Moravian region will formulate the fourth generation of innovation strategy. It will place even greater emphasis on investments in education, increase support for rural and suburban areas of South Moravian region and will increase focus on encouraging the growth of already established companies. A big commitment is to ensure the greatest possible benefits of investing in research centers for the regional economy [5]. South Moravia region in Czech Republic in the middle of Europe has got a traditional strong and expanding basis in the research and development area formed by college students and scientists and industry. The structure of these students and scientists is also favorable because it is focused on disciplines of biology and engineering. The key approach how to improve the situation is to support innovative small and medium enterprises with a high added value that direct their attention to the introduction of novel and better products and services and also to the introduction of new approaches. A political consensus of all parties involved represent a cardinal advantage in a process of introducing the system supporting the innovative business [10].

Regional economies are keys to innovation and growth. There is a wealth of evidence and practical examples, which confirms that regions and cities play an important role in developing innovation by being the home of industrial clusters, competence centers, incubators, technology parks and many other types of formal and informal innovation spaces. Successful regions and cities become European or global nodes of innovation, technology networks and value chains [11]. Regions have an insight into their own innovation systems, as well as the capacities to mobilize regional innovation stakeholders through specific policy instruments. On the other hand, regional stakeholders have a good understanding of regional environmental performances, as well as the capacities and competences to take local action to promote environmental sustainability [9]. Universities Community associations Research organizations Business Community Consumers Environmental, innovation \& energy agencies Regional Authorities, National Government EU. Regions have both the expertise and the capacity to effectively address both innovation and sustainability challenges. In many instances, connecting these expertise, creating collective capacities to act and coming up with innovative solutions is place specific. Eco-innovation, like any other innovation, should be understood as "occurring because of what are often geographically proximate concentrations and interactions amongst small, fast-moving systems of innovators and their networks" [3].

The Regional Innovation Strategy of the Moravian region represents a set of measures, sub measures and tools that should be implemented to ensure the development of innovations. The first version of the Regional Innovation Strategy was created in 2002 and it came into being in the context of that time and the environment. Since that time substantial changes happened in the environment, in priorities of the Czech Republic and in the economic area of South Moravia as well as in possibilities to obtain external financial means for innovations (in particular owing to the admission of the Czech Republic to the European Union). The sectors of business enterprises, universities and colleges as well as supporting organizations in 
South Moravia are undergoing a dynamic development and because of this an obvious need to update the innovation support strategy appeared. Universities, the regional political representation and representatives of the City of Brno have managed to find a common ground and came to an agreement regarding goals that are mentioned in the Regional Innovation Strategy.

The need to update the strategy has emerged mainly from substantial changes in the environment. The first part of changes includes changes on the top level, especially the admission of the Czech Republic to the European Union, the attention of the government paid to support small and medium business enterprises and emphasizing of innovations as a tool for increasing the competitiveness of Czech enterprises. After the admission of the Czech Republic to the European Union the possibility of exploiting a financial support in the form of structural funds has proved to be a great stimulus. These funds (especially the Operational Programme Industry and Entrepreneurship) are aimed at a support of innovations and increase of the competitiveness of Czech enterprises generally.

The second part of changes includes local changes in South Moravia. It concerns mainly the change of the infrastructure of industrial companies, the development of new industries, altering requirements of companies and preferences of the society as a whole. In this connection we should mention the expanding activities of universities and colleges, the development of the biotechnology sector, a larger exploitation of grant programs from the part of companies, a relocation of companies to South Moravia and efforts made to put results of the research and development widely into practice.

The third part of changes includes the general development of the society, improving the standards of living, the development of the tertiary sector and companies oriented more to their basic businesses. The open innovation phenomenon has developed from a small club of innovation practitioners, mostly active in high-tech industries, to a widely discussed and implemented innovation practice. Simultaneously, a small community of management researchers has recently developed into an established research field. Once a field grows rapidly there is a danger that it may become a shortterm fashion [8].

One of the very important tool, which was implemented into regional innovation strategy is model of Open innovation session as an efficient tool of strategic management.

\section{Open innovation session}

Open Innovation Session (OIS) is a one-day meeting with potential technological partners tailored to the specific demands of both Czech and international corporations. The aim of the OIS meeting is to quickly and effectively present possible solutions to a technological problem or challenge defined by a client corporation, and to connect the company with suitable partners, potential suppliers of solutions. For companies South Moravian Centre organizes a tailor-made process from identifying the long-list of potential suppliers of solution, reaching out to them, organizing the logistics of a 
meeting, including the premises. Together with the client South Moravian Centre determine the technological areas of their interest, or directly determine specific technological problems where a solution may come from cooperation with external partner. A typical client of OIS is a hi-tech corporation and aim is to connect them with other, small or medium-sized companies, or research organizations, that suit the best their requirements. First there are preselect a long list of potential partners and then, together with the client, are selected those firms and research organizations that are contacted on behalf of the company. After it is organized a joint meeting - an Open innovation session - where experts from the selected companies and research organizations present their technological solutions. At the OIS proper, the participants each in turn present their respective technology or solution, followed by a discussion. This allows the client to compare the quality of different parties - their offerings and technical solutions - and make up their mind about future cooperation. The OIS may not only lead to partnerships, but can often work as an opportunity for creative problem solving. This tool demonstrate the interest of the local government in support strategic management of local companies.

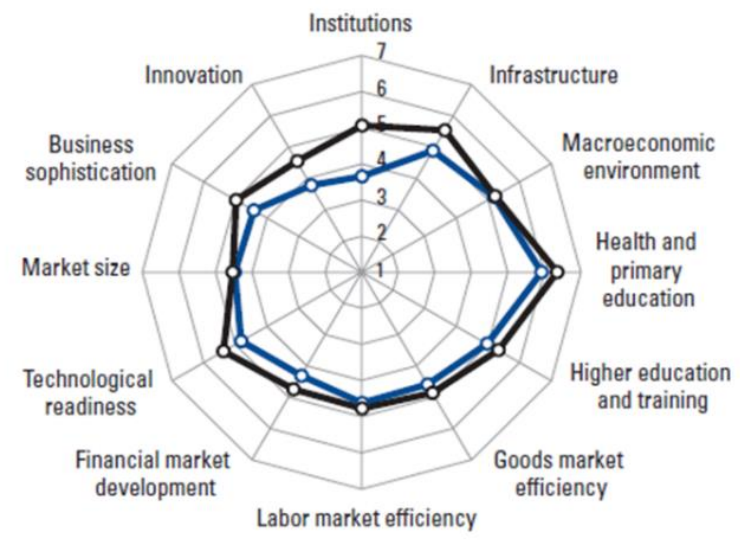

$-\infty$ Crech Republic $\quad-\infty$ Innovation-driven economies

Fig. 1. Global Competitiveness factors; 7 worst; 1 best [6], inner circle represents Czech Rep.

The symbolic meaning of strategic management's tools that demonstrate the interest of the local government within the generally very poor institutional environment of the Czech Republic The development of the knowledge economy will also be strongly influenced by the continued interest of foreign companies present and not yet present in the Czech Republic. In this context, a fundamental problem in the Czech Republic is the poor quality of the Institutional Environment (see fig. 1 lagging behind developed economies), which significantly reduces the investment attractiveness of the country as a whole (and thus logically also the South Moravian Region). The importance of a high-quality institutional environment (as an enabling 
factor) grows with the sophistication of economic activities (e.g. conditions for a functioning venture capital market).

The symbolic meaning of tools that demonstrate the interest of the local government within the generally very poor institutional environment of the Czech Republic The development of the knowledge economy will also be strongly influenced by the continued interest of foreign companies present and not yet present in the Czech Republic. In this context, a fundamental problem in the Czech Republic is the poor quality of the Institutional Environment (see lagging behind developed economies), which significantly reduces the investment attractiveness of the country as a whole (and thus logically also the South Moravian Region). The importance of a high-quality institutional environment (as an enabling factor) grows with the sophistication of economic activities (e.g. conditions for a functioning venture capital market).

\section{Open innovation model as a tool of strategic management}

Making companies able to compete is the purpose of strategic management. To that end, putting strategic management plans into practice is the most important aspect of the planning itself. Plans in practice involve identifying benchmarks, realigning resources - financial and human - and putting leadership resources in place to oversee the creation, sale, and deployment of products and services [1]. Strategic management extends to internal and external communication practices as well as tracking to ensure that the company meets goals as defined in its strategic management plan and open innovation is one of part which is complementary with all set of tools for strategic planning [9]. The use of strategic management in many areas has been able to increase the efficiency of institutions and centers and plays an effective role in their success [2]. William Darden from Hershey National Track Company takes its success into account of strategic management. Alfred Thomas Chandler, professor at Harvard University, published its studies over large American corporations and explained their senior executive managers' strategic decision-making process. He also demonstrated that how strategic decisions can lead to excel in a competitive environment [1]. The results have revealed that the use of strategic management increase the efficiency of car companies, for example Bahman Khodro Company increased the number of its produced cars up to 6000 units in 2013. Furthermore, customer satisfaction level increased to 73 per cent in this year. Using a dynamic, forward-looking, and holistic discipline, strategic management is considered as a solution for too many today's organizational issues [1]. Strategic management foundations are located based on managers' understanding of their rival companies, markets, prices, raw material suppliers, distributors, government, creditors, shareholders, and customers in all over the world [4]. Today, many institutions supply a high percentage of their resources from external sources and economic and commercial enterprises and institutions. These limited resources and incentives to attract top students have created a competitive market for these institutions. In today's knowledge based economy, 
higher education institutions as development center for human resources play an important role in the growth and development of countries.

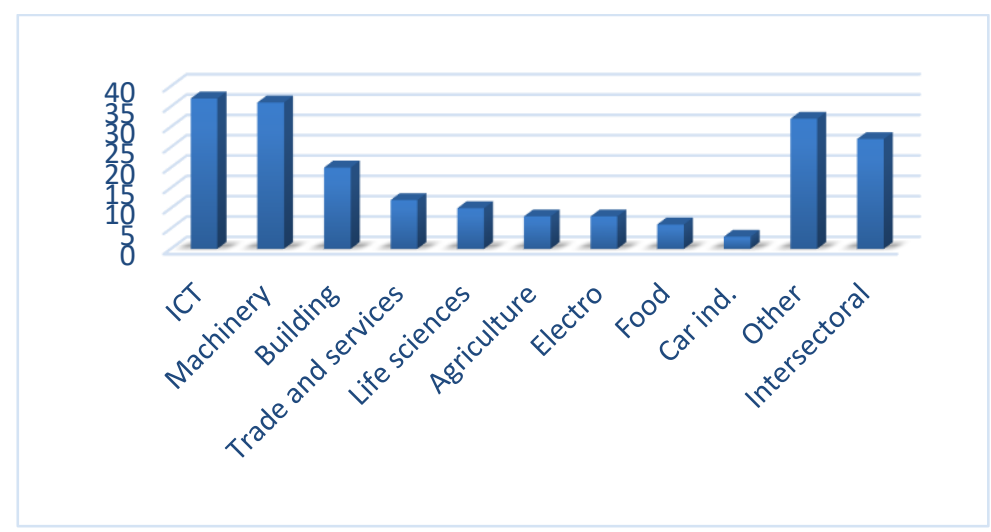

Fig. 2. A Sectorial orientation of applicants of Open innovation session model

The largest number of companies which used Open innovation session model as a tool of strategic management were mostly focused on machinery and ICT field.

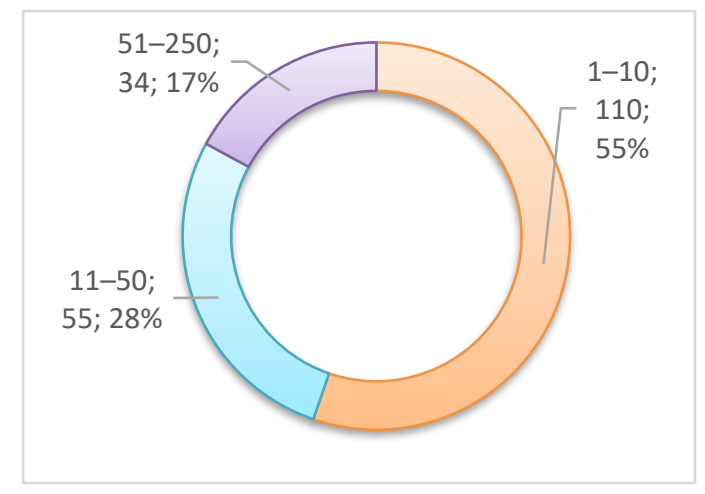

Fig. 3. Size of applicants of Open innovation session model (acc. number of employees)

More than half of all applicants were companies with number of employees up 51 to 250.More than half of applicants have never worked on project with university before. Here we can see the main impact of Open innovation session model.

\section{Conclusion}

Identify new collaboration opportunities; knowledge of regional, as well as Czech national ecosystem will allow companies to tap into the pool of expertise and talent of start-ups, SMEs, as well as academic institutions in South Moravia, or across the 
Czech Republic. Regional strategy is partnership of South Moravian companies, local scientists, public authorities and other parties connected to development in the region. Working together innovation strategy has managed to create hundreds of skilled jobs in dozens of new high - tech companies. One of the target is to reach successful cooperation between industry and universities. One of the very important tool, which was implemented is model of Open innovation session as a tool of strategic management. The main benefits of Open innovation session model are: Simplify work and save time for the company only explain its challenge once, and facilitators take over the tedious job of pre-selection and routine communication with potential partners and multiply your offer to the relevant partners across the region/country. Interactive format may generate more ideas - the design of the Open innovation session model allows several participants to interact during the session which increases the chances of coming up with unexpected solutions to the identified challenges.

The tool perspective: Opening up the innovation process requires a set of instruments. Those tools, for example, enable customers to create or configure their own product with tools kits or enable companies to integrate external problem solvers or idea creators via websites. Especially the low degree of interconnection of the corporate and academic sectors, which prevents the full use of the knowledge base of the region to create the foundations of the long-term prosperity of the local economy. The mission of the program is to initiate the creation of new relationships between companies and researchers from the South Moravian Region, while it is expected that some of them will gradually develop into long-term collaboration. The primary objective is the initiation of new collaboration, defined as collaboration that continues even after the end of the project, while there was no collaboration between the two parties before entry into the program. Initiate the creation of new collaboration reducing transaction costs associated with the commencement of collaboration. Contribute to entrepreneurs' and researchers' understanding of each other, especially in the very different contexts of the objectives and conditions of collaboration [12]. Increase demand within research institutes for greater functionality of internal procedures and rules regarding collaboration of researchers and companies. Build trust in local public administration. Improve the image among companies and researchers. Reinforce the perception of City Brno and the south Moravian region as leader in the knowledge economy promotion in Europe. Bring symbolic value to foreign investors. Demonstrate the interest of the local government to create conditions for the development of knowledge-intensive operations of transnational corporations (Honeywell, Microsoft, ON Semiconductors, etc.). Besides the "technical" objectives of the model, it is also necessary to emphasize its marketing objectives, though some of them came into existence only during the program. The implications and trends that underpin open innovation are actively discussed in terms of strategic, organizational, behavioral, knowledge, legal and business perspectives and could be seen as a part of strategic management of an organization's resources to achieve its goals and objectives. The model can be applied towards improving the very low trust in public administration. It also contributes to the development of the image of Brno as a Centre where the knowledge economy is smartly supported. Two- 
thirds of supported companies had their partner from the research sector solve a specific technical problem for them. More than two-thirds of companies found a researcher who was able and willing to help them.

Therefore, this is a purely subjective perception of the benefit by the respondents. The objective of the Open innovation session model was also to contribute to the greater understanding of each other between entrepreneurs and researchers, especially in the very different context of objectives and conditions with which the parties approach collaboration. In $68 \%$ of cases the main reason of cooperation by companies side were knowledge of specific researcher's team.

The data show that participation in the program Open innovation session led to a shift in the perception of the objectives, needs and conditions of the business and academic world. Participants in the program are now more aware of the potential hidden in collaboration and at the same time are better prepared to organize this collaboration. After the end of the project, companies continuing in collaboration with new partners from the local research sector. And one of the very important tool, which was implemented is model of Open innovation session as a tool of strategic management.

Acknowledgement. This work was supported by the internal specific research "Evaluation of investments in the concept of Industry 4.0“ Faculty of Informatics and Management, University of Hradec Králové.

\section{References}

1. Amoli, S. J., Aghashahi, F.: An Investigation on Strategic Management Success Factors in an Educational Complex Procedia - Social and Behavioral Sciences, Volume 230, 12 September, pp. 447-454, (2016).

2. Beck, K.: Extreme Programming Explained: Embrace Change. Amsterdam: AddisonWesley Longman. (2000)

3. Boutellier, R., Gassmann, O., Macho, H., Roux,M.: Management of dispersed R\&D teams. R\&D Management, 28, 1, pp. 13-25. (1998)

4. Boutellier, R.., Gassmann, O., Zedtwitz, M.: Managing Global Innovation, Uncovering the Secrets of Future Competitiveness, 3rd revised edn. Berlin: Springer. (2008)

5. Csank, P.: Interim Evaluation Results, South Moravian Centre, (2013).

6. World economic forum WEF - Global Competitiveness Report 2011-12; (2012).

7. Chesbrough, H.W.: Open Innovation: The New Imperative for Creating and Profiting from Technology. Cambridge, MA: Harvard Business School Publishing. (2003).

8. Chesbrough, H.W.: Open Business Models: How to Thrive in the New Innovation Landscape. Cambridge. (2006).

9. Cooke, L.: Transition regions: Regional-national eco-innovation systems and strategies, Progress in Planning, 76, pp. 105-146 In: Connecting Smart and Sustainable Growth through Smart Specialisation. A practical guide for ERDF managing authorities; ISBN: 978-92-79-27345-2 (2011).

10. Matulova, P.: Innovation Voucher Programme: Effective Tools of Transfer Technology and Open Innovation 24th IBIMA Conference Milan, Italy 6-7 November, (2014). 
11. OECD: Local Economic and Employment Development Policy Approaches in OECD Countries, A Review, www.oecd.org/document/17/0,3343,en_2649_34417_42750737 _1_1_1_1,00.html, last access 2017/12/1.

12. Roper, S., Love, J.H., Cooke, P., Clifton N.: The Scottish Innovation Systems: Actors, Roles and Actions: Report for the Scottish Executive, (2005). 